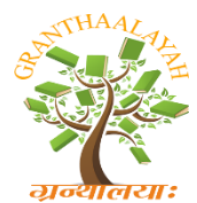

INTERNATIONAL JOURNAL OF RESEARCH GRANTHAALAYAH A knowledge Repository

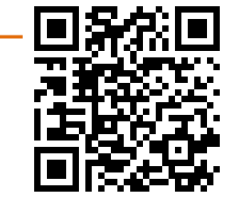

Science

\title{
STUDY OF PREOPERATIVE CLINICAL AND INVESTIGATIVE FACTORS PREDICTING DIFFICULT LAPAROSCOPIC CHOLECYSTECTOMY
}

\author{
Dr. Deepak Verma ${ }^{1}$, Dr. Ratan ${ }^{2}$, Dr. Nemi Chand ${ }^{2}$ \\ ${ }^{1}$ Senior Professor and Head of the Department, Department of Surgery, Dr. S. N. Medical \\ College, Jodhpur, Rajasthan India \\ ${ }^{2}$ Senior Resident, Department of Surgery, Dr. S. N. Medical College, \\ Jodhpur, Rajasthan India
}

\begin{abstract}
Background: Laparoscopic cholecystectomy is one of the most commonly performed surgical procedure with the advantage of short hospital stay, cosmetic, less post-operative pain and early return to work and thus ultimately cost effective. However, certain factors can make the procedure difficult and such patients many do not enjoy benefit of laparoscopic procedure particularly longer hospital stay.

Aim: To determine various factors on clinical, pathological and radiological grounds to predict difficult laparoscopic cholecystectomy.

Material and Method: 200 patients admitted in surgical ward with a diagnosis of Chronic Calculus cholecystitis to be selected for laparoscopic cholecystectomy were subject of this study. Age, Sex, BMI, number of previous attack, previous abdominal surgery, past history of pancreatitis and jaundice, signs of acute cholecystitis, leucocytosis, CRP, Liver function tests, serum amylase and lipase, GB wall thickness, presence of pericholecystic fluid, status of GB and anatomical variation were various factors studied.

Results: Age > 50 years, male sex, BMI>30, more than 4 attacks, signs of cholecystitis, leucocytosis $>11,000 / \mathrm{cu} \mathrm{mm}$, increased GB wall thickness, presence of pericholecystic fluid and overdistended or contracted gall bladder are associated with difficult laparoscopic cholecystectomy.

Keywords: Prediction; Difficult; Laparoscopic Cholecystectomy.

Cite This Article: Dr. Deepak Verma, Dr. Ratan, and Dr. Nemi Chand. (2020). "STUDY OF PREOPERATIVE CLINICAL AND INVESTIGATIVE FACTORS PREDICTING DIFFICULT LAPAROSCOPIC CHOLECYSTECTOMY." International Journal of Research - Granthaalayah, 8(3), 207-213. https://doi.org/10.29121/granthaalayah.v8.i3.2020.144.
\end{abstract}




\section{Introduction}

Gallstone disease is one of the most common problems affecting the digestive tract. The prevalence of gallstones is related to factors like age, gender, and ethnic background. In India the prevalence is estimated to be around 4\% [1] changing incidence in India is mainly attributed to westernization of diet, change in socioeconomic structure and availability of ultrasound as investigation in both rural and urban areas. The National Institute of Health (NIH) consensus development conference in the year 1992 concluded that laparoscopic cholecystectomy provides a safe and effective treatment for most patients with symptomatic gallstones [2]. Laparoscopic cholecystectomy is the gold standard treatment for cholelithiasis. It has now become one of the most common operations performed by general surgeons. Since the introduction of laparoscopic cholecystectomy, the number of cholecystectomy performed in India has been increased due to widespread use of radiological investigation for screening. The advantages of laparoscopic cholecystectomy are earlier return to bowel function, less postoperative pain, cosmetic, shorter length of hospital stay, earlier return to full activity, and decreased overall cost. Attempts can be made in all cases of gall stone diseases with laparoscopic procedure except for patients with bleeding diathesis and patients not fit for general anesthesia. However, of all Laparoscopic Cholecystectomy, 1-13\% requires conversion to an open for various reasons [3]. Thus, for surgeons it would be helpful to establish criteria that would assess the possibility of difficult laparoscopic cholecystectomy therefor higher risk of conversion particularly if can be done preoperatively. Preoperative prediction of the risk of conversion or difficulty of operation is an important aspect of planning laparoscopic surgery. The purpose of our prospective study was to analyze various risk factors and to predict difficulty difficult cholecystectomy preoperatively by clinical, pathological and radiological assessment.

Aim: The aim of our study was to evaluate various clinical, pathological and radiological factors to predict difficult laparoscopic cholecystectomy preoperatively.

\section{Materials and Methods}

The present prospective study was conducted in department of general surgery at MDM hospital attached to Dr. S.N. Medical College, Jodhpur (Rajasthan). 200 cases were taken and following individual factor were noted preoperatively in a predefined proforma. All cases were operated by single surgeon to avoid individual bias depending on surgeon's experience and skill. Patients with choledocholithiasis and other ailments like requiring additional surgical procedure and previous history of multiple abdominal wall surgeries (scarred abdomen) were also excluded.

Preoperative risk factors studied

\begin{tabular}{|l|c|c|}
\hline & Factor & Limit \\
\hline History & Age & $<50 />50$ years \\
\hline & Sex & Male / Female \\
\hline & BMI & $<30 />30$ \\
\hline & Number of previous attacks & $<4 />4$ \\
\hline & Previous Abdominal Surgery & Present (One) / Absent \\
\hline & Past History of Pancreatitis & Present / Absent \\
\hline & Past History of Jaundice & Present / Absent \\
\hline Clinical Examination & Signs of Acute Cholecystitis & Present / Absent \\
\hline
\end{tabular}




\begin{tabular}{|l|c|c|}
\hline Pathological Findings & Leucocytosis & $<11,000 />11,000 / \mathrm{cu} \mathrm{mm}$ \\
\hline & Liver Function Tests & Normal / Altered \\
\hline & CRP & Positive / Negative \\
\hline Radiological Findings & Serum Amylase / Lipase & Normal / Altered \\
\hline ( USG / MRCP ) & GB wall thickness & Normal / Increased \\
\hline & Pericholecystic Fluid & Present / Absent \\
\hline & Status of GB & Normal / Altered \\
\hline & Anatomical Variation & Present / Absent \\
\hline
\end{tabular}

Duration of surgery, deviation from the classical method of 4-port cholecystectomy using closed pneumoperitoneum from umbilical port, difficulty encountered during the procedure, remedial measure taken for difficulty and total duration of surgery will be recorded on proforma.

On the basis of surgeon's comment on difficult or easy cholecystectomy, average time taken for easy cases will be calculated and if the time taken is more than average time, it will be considered as difficult laparoscopic cholecystectomy. Each studied factor will be individually assessed statistically to evaluate if the particular factor is responsible for difficult laparoscopic cholecystectomy.

As mentioned earlier, all cases were performed by a single surgeon using $\mathrm{CO}_{2}$ pneumoperitoneum with $10-15 \mathrm{~mm} \mathrm{Hg}$ intraperitoneal pressure and using standard two $5 \mathrm{~mm}$ and two $10 \mathrm{~mm}$ ports. The study was approved by Institutional Ethical Committee with informed consent from participants.

\section{Results}

Table 1: Number of patients having Easy / Difficult LC

\begin{tabular}{|l|cc|}
\hline Postoperative Conclusion & Number & Percentage \\
\hline Easy & 108 & 54 \\
\hline Difficult & 92 & 46 \\
\hline
\end{tabular}

Table 2: Duration of Surgery in Easy versus difficult Lap. Cholecystectomy

\begin{tabular}{|l|c|c|c|c|}
\hline $\begin{array}{l}\text { Postoperative } \\
\text { Conclusion }\end{array}$ & N & Percentage & $\begin{array}{c}\text { Mean time duration of LC } \\
\text { (In minutes) }\end{array}$ & P value \\
\hline Easy & 108 & 54 & $26.48 \pm 4.24$ & \\
\hline Difficult & 92 & 46 & $45.28 \pm 8.11$ & $<0.0001$ \\
\hline Total & 200 & - & - & - \\
\hline
\end{tabular}

Table 3: Individual Factor, Intraoperative time and Statistical values.

\begin{tabular}{|c|c|c|c|c|c|c|}
\hline & $\begin{array}{l}\text { Preoperative } \\
\text { risk factors }\end{array}$ & Variable & $\begin{array}{c}\text { Mean } \\
\text { operative } \\
\text { time(minutes) }\end{array}$ & $\%$ & P value & Significance \\
\hline \multirow[t]{2}{*}{ History } & \multirow[t]{2}{*}{ Sex } & Male & $36.05 \pm 7.29$ & $26 \%$ & \multirow[b]{2}{*}{$<0.001$} & \multirow[b]{2}{*}{ Significant } \\
\hline & & Female & $29.12 \pm 7.92$ & $74 \%$ & & \\
\hline
\end{tabular}


DOI: 10.5281/zenodo.3734232

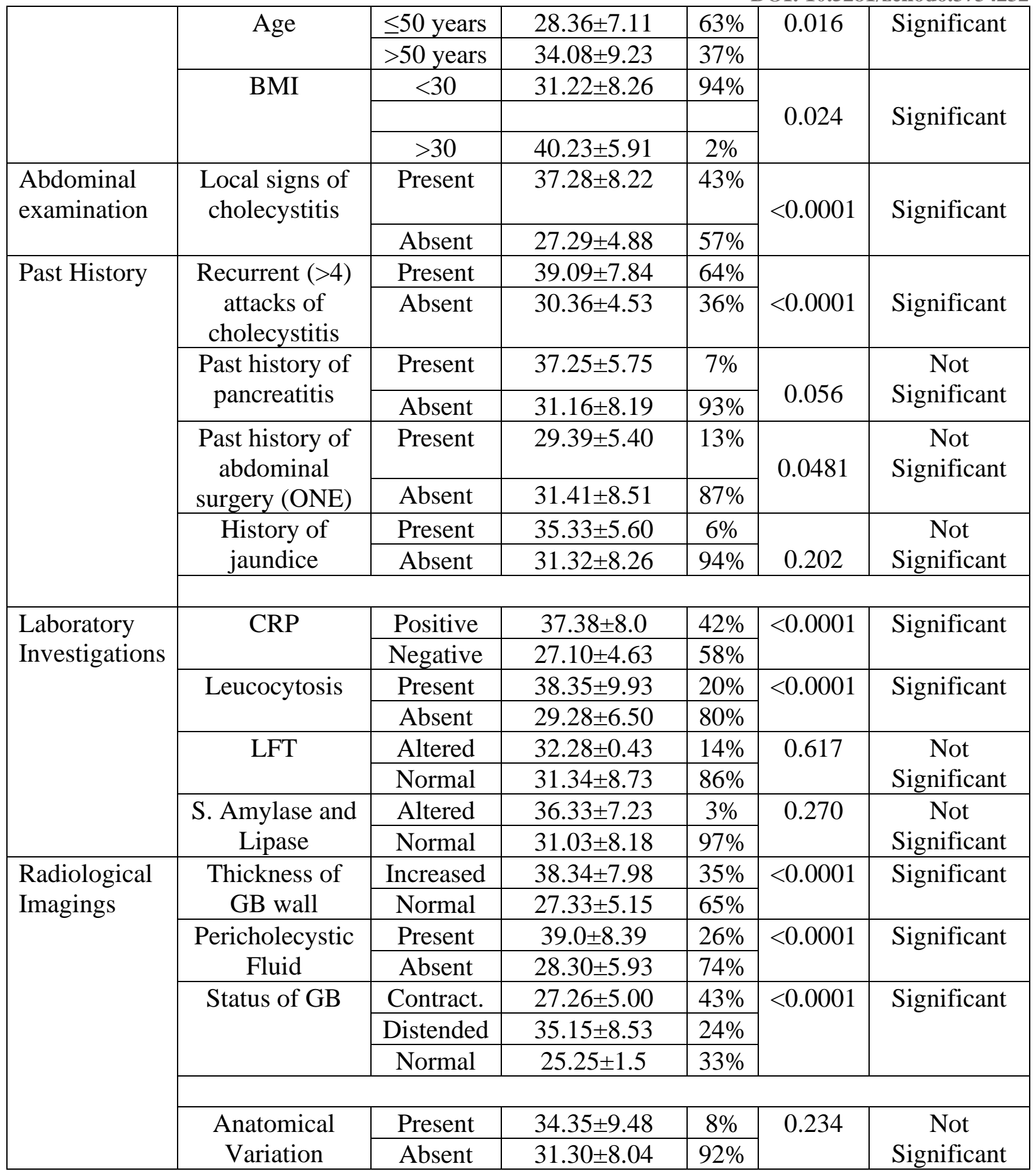

Statistically significant risk factors are age more than 50 years, male sex, BMI more than 30, recurrent attacks (more than 4), Leucocytosis more than 11,000/cu mm, Positive CRP, thick walled gall bladder, presence of pericholecystic fluid, contracted or overdistended Gall bladder. These factors in preoperative assessment indicate difficult laparoscopic cholecystectomy. 


\section{Discussion}

Gallstone disease is one of the most common problems affecting the digestive tract. The prevalence of gallstones is related to factors like age, gender, and ethnic background. In India the prevalence is estimated to be around 4\% (1). laparoscopic cholecystectomy provides a safe and effective treatment for most patients with symptomatic gallstones [2]. Laparoscopic cholecystectomy is the gold standard treatment for cholelithiasis. The advantages of laparoscopic cholecystectomy are earlier return to bowel function, less postoperative pain, cosmetic, shorter length of hospital stay, earlier return to full activity, and decreased overall cost. However, conversion to open from laparoscopic cholecystectomy depends on various factors besides experience of surgeon.

In present study, 54\% patients had easy laparoscopic procedure and the time taken in completion of procedure was $26.48+/-4.24$ minutes whereas in remaining $46 \%$ patients the procedure was difficult and took $45.28+/-8.11$ minutes. The statistical difference was highly significant ( $\mathrm{p}$ value $<0.0001)$.

Mean duration of surgery was $35.65 \pm 7.29$ minutes in male patients and $29.62 \pm 7.92$ minutes in female patients ( $\mathrm{p}$ value is $<0.001$ significant). Russel et al ${ }^{(4)}$ have suggested that men tend to present late as they pay less attention to subtle symptoms, therefore, may have more advanced disease in form of adhesions, fibrosis, thick walled GB. Similarly mean duration of surgery in patients' $\leq 50$ years was $29.66 \pm 7.11$ minutes and in $>50$ years, it was $33.68 \pm 9.23$ minutes ( $\mathrm{p}$ value 0.016 significant). Increased age is associated with an increased probability of multiple attacks of cholecystitis and also increased frequency of upper abdominal surgeries. Randhawa et al ${ }^{(5)}$ found that patients more than 50 years surgery was associated with more difficulties.

Obesity causes difficulty in creation of pneumoperitoneum and port placement due to thick abdominal wall and umbilicus being placed downwards. Obesity also causes in difficulty in dissection in Calot's triangle because of excessive intraperitoneal and omental fat. Nachnani et al (7) and Hussain et al ${ }^{(8)}$ have found BMI $>30$ to be significantly associated with difficulty in umbilical port entry and creating pneumoperitoneum. In present study also the difference in operating time in patients above BMI of 30 was statistically significant. BMI $>27.5$ was predictor of difficult cholecystectomy as demonstrated by Prashant et al ${ }^{(6)}$.

In patients with local signs of cholecystitis, mean duration of surgery was $36.88 \pm 8.22$ minutes, which is statistically significant as compared to duration of surgery in patients without any sign of local inflammation. and without signs of inflammations ( $\mathrm{p}$ value $<0.0001$ ) Presence of acute cholecystitis with pericholecystitis makes LC difficult due to anatomical distortion of calot's triangle, adhesions and haemorrhage during procedure. Similar difficulties were observed by Alponat et al ${ }^{(9)}$, Kama et al ${ }^{(10)}$, and Vivek et al ${ }^{(11)}$.

In patients with more than four recurrent attacks of symptoms, mean duration of surgery was $38.69 \pm 7.84$ minutes while in those with less than four attacks of recurrent attacks, it was $29.96 \pm 4.53$ minutes, $p$ value is $<0.0001$ (statistically significant). Prashant et al (6) also reported similar findings in his study. Nidoni ${ }^{(12)}$ reported that even more than two attacks will have significantly high risk of difficulty in laparoscopic cholecystectomy in a study of 180 patients. 
In patients with leucocytosis, mean duration of surgery was $37.95 \pm 9.93$ minutes and with normal leucocytes it was $29.28 \pm 6.50$ minutes ( $p$ value <0.0001 statistically significant). Leucocytosis indicates ongoing inflammation due to active infection of biliary system leading to thickening of GB wall, pericholecystic edema/collection, adhesions to surrounding structures and GB distension $\left({ }^{12)}\right.$.

In patients with CRP positive, duration of surgery was $37.38 \pm 8.0$ minutes and negative CRP it was $26.70 \pm 4.63$ minutes ( $p$ value $<0.0001$ - significant). Vivek et al ${ }^{(11)}$ reported a strong association between CRP and difficult LC.

Radiological investigations like ultrasonography and MRCP are key investigations in cholelithiasis to know the status of gall bladder (normal or overdistended / contracted), presence of pericholecystic fluid and anatomical variation in ductal and or arterial system.

In patients with increased GB wall thickness duration of surgery was $38.34 \pm 7.98$ minutes and without it was a $37.33 \pm 7.32$ minutes ( $\mathrm{p}$ value $<0.0001$ ). In patients with pericholecystic edema, mean duration of surgery was $39.0 \pm 8.39$ minutes whereas without edema it was $28.30 \pm 5.93$ minutes ( $\mathrm{p}$ value $<0.0001$ ) Alphonat et al ${ }^{(9)}$ and kama et al ${ }^{(10)}$ have demonstrated similar results. Overdistended gall bladder is difficult to handle during laparoscopic cholecystectomy and contracted gall bladder is difficult to dissect particularly Calot's triangle dissection. In this study also normal GB could be removed in $25.25 \pm 1.5$ minutes and it took longer to dissect overdistended and contracted GB. Singh et al ${ }^{(13)}$ and Lal et al ${ }^{(14)}$ reported similar results in their study.

Advantages of preoperative prediction of difficult laparoscopic cholecystectomy include information to patient and relatives regarding difficult procedure, higher chances of conversion to open procedure. In case of minimizing conversion, operating surgeon can ensure availability of additional equipment's like additional trocars, newer energy sources like harmonic scalpel / vessel sealer, ICG compatible comers or at least a senior consultant for patient's benefit. Counselling can also be done for prolonged hospital stay (15).

However, in patients with past history of pancreatitis, jaundice, abdominal surgery, altered LFT, raised serum. amylase or lipase, dilated CBD and anatomical variation were not associated with statistically significant difference in operative time of laparoscopic cholecystectomy.

\section{Conclusion}

We conclude that the difficult laparoscopic Cholecystectomy can be predicted preoperatively based on age more than 50 years, male sex, BMI more than 30, more than 4 attacks of cholecystitis, leucocytosis more than 11,000 per cu mm, increased GB thickness, pericholecystic oedema/collection and overdistended or contracted Gall bladder. Other factors like past history of jaundice or pancreatitis, previous abdominal surgery, altered liver function and amylase or lipase level and preoperatively detected anatomical variation does not influence ease of dissection in laparoscopic cholecystectomy 


\section{References}

[1] Tendon, R. "Diseases of gallbladder and biliary tract". API text book of medicine, Dr. Siddarth N Shah, 2003; 7th edition: Pp. 642-44.

[2] Conference NC.: Gallstones and laparoscopic cholecystectomy. JAMA. 1992;269:1018-24.

[3] Sharma SK, Thapa PB, Pandey A, Kayestha B, Poudyal S.: Predicting difficulties during laparoscopic cholecystectomy by preoperative ultrasound. Kathmandu University Medical journal. 2007;5(17):8-11.

[4] Russell JC, Walsh SJ, Reed-Fourquet L, Mattie A, Lynch J.: Symptomatic cholelithiasis: A Different disease in men? Ann Surg. 1998;227:195-200.

[5] Randhawa JS, Pujahari AK. Preoperative prediction of difficult lap chole: A scoring method. Indian J Surg.2009;71:198-201.

[6] Prashant KD, Subodh P Ugane.: Factors predicting difficult laparoscopic cholecystectomy: A single-institution experience.Year 2014, Vol.-4, Issue-1, pages 3-7

[7] Nachnani, J, Supe A: Pre-operative prediction of difficult laparoscopic cholecystectomy using clinical and ultrasonographic parameters.. Ind J Gastroenterology 2005 Vol 24 January - February

[8] Hussien M, Appadurai IR, Delicata RJ, Carey PD.: Laparoscopic cholecystectomy in the grossly obese: 4 years experience and review of literature. HPB (Oxford)2002;4:157-61.

[9] Alponat A, Kum CK, Koh BC, Rajnakova A, Goh PM.: Predictive factors for conversion of laparoscopic cholecystectomy. World J Surg. 1997;21:629-33.

[10] Kama NA, Kologlu M, Doganay M, Reis E, Atli M, Dolapci M. A risk score for conversion from laparoscopic to open cholecystectomy. Am J Surg. 2001 Jun; 181(6):520-5.

[11] Vivek, MAKM, Augustine, AJ and Rao.R : A comprehensive predictive scoring method for difficult laparoscopic cholecystectomy J Minim Access Surg. 2014 Apr-Jun; 10(2): 62-67

[12] Nidoni R, Udachan TV, Sasnur P et al: Predicting difficult laparoscopic cholecystectomy based on clinicoradiological assessment. J.Clin Diagn Res, 2015, Dec:9(12);PC-09-PC-12

[13] Singh K, Ohri A. Difficult laparoscopic cholecystectomy: A large series from north India. Indian J Surg 2006;68:205-8

[14] Lal P, Agarwal PN, Malik VK, Chakravarti AL. A difficult Laparoscopic cholecystectomy that requires conversion to open procedure can be predicted by preoperative ultrasonography.JSLS 2002;6:59-63.

[15] Joshi MR, Bohara TP, Rupakheti S, Parajuli A, Shrestha DK, Karki D, Laudari U. Preoperative prediction of difficult laparoscopic Cholecystectomy. JNMA,.2015 Oct-Dec;53(200):221-226.

*Corresponding author.

E-mail address: drdeepakv@ymail.com 